\title{
Política Pública de Agroindustrialização na Agricultura Familiar: Uma Análise do Pronaf-agroindústria
}

\author{
Valdemar João Wesz Junior ${ }^{1}$
}

Resumo: Com o passar dos anos, o Pronaf (Programa Nacional de Fortalecimento da Agricultura Familiar) foi se estruturando e ampliou significativamente seu campo de atuação. Além do aumento dos recursos, contratos e número de agricultores beneficiados, uma importante inovação desse programa foi a inclusão de novas linhas de financiamento, seja através da inserção de segmentos até então renegados pelas políticas agrícolas ou pelo reconhecimento e legitimação das atividades diferenciadas no meio rural, como é o caso da agroindustrialização em escala familiar. O objetivo central desse artigo é analisar a política de crédito rural direcionada às agroindústrias familiares (Pronaf-Agroindústria), trazendo em evidência a constituição, elaboração, implementação e os resultados alcançados por essa linha de financiamento. Além disso, é discutido o processo de reformulação das condições de acesso ao crédito ao longo dos últimos anos, problematizando o novo portfólio que se alcançou com a efetivação do Programa Mais Alimentos. Os resultados deste trabalho destacam a flexibilização das condições financeiras do PronafAgroindústria (redução da taxa de juros, aumento do teto financiado e alastramento no público-alvo), alterando significativamente o foco de atuação da política (que deixa de ser exclusivamente as pequenas agroindústrias familiares e passa a englobar, também, as grandes cooperativas de leite).

Palavras-chaves: políticas públicas, agroindústria familiar, crédito rural.

\footnotetext{
${ }^{1}$ Doutorando do Programa de Pós-Graduação de Ciências Sociais em Desenvolvimento, Agricultura e Sociedade (CPDA/UFRRJ). E-mail: jwesz@yahoo.com.br
} 
568 - Política Pública de Agroindustrialização na Agricultura Familiar: Uma Análise do Pronafagroindústria

Abstract: During the years, since its implementation, Pronaf has become more structured and has significantly increased its action field. Alongside the increase of resources, contracts, and number of benefited agriculturists, an important innovation of this program was the inclusion of new lines of funding, either through inserting segments until then, excluded from the agricultural policies, or including, recognizing, and legitimizing different activities performed in rural areas, such as familiar agroindrustialization. This paper aims to analyze the family agroindustry oriented rural credit policy (Pronaf-agroindustry), evidencing the constitution, elaboration, implementation and results of this line of funding. Moreover, the paper discusses the process of reformulation in the access conditions to the credit during recent years, analyzing the new portfolio constituted by a program called Mais Alimentos. The results of this paper highlight the flexibility of Pronaf-Agroindustry's financial conditions (reduction of interest rate, increase of the financed ceiling, and spread of the target public), which changes significantly the policy focus (it no longer benefits small family agroindustries exclusively, but also includes major milk cooperatives).

Key-words: public policies, family agroindustry, rural credit.

Classificação JEL: Q18.

\section{Introdução}

Após um longo período de privilégio da política agrícola brasileira aos grandes e médios produtores, espacialmente localizados na região Sul e Sudeste e com produções destinadas à exportação (LEITE, 2001), a década de 90 passa a presenciar a modificação parcial do escopo de atuação dos mecanismos de intervenção voltados ao meio rural. Um marco dessa transformação foi a implementação do Pronaf(Programa Nacional de Fortalecimento da Agricultura Familiar), que, ao direcionar suas linhas de crédito a um público marcado pela renegação das políticas públicas, confirmou o reconhecimento e a legitimação do Estado em relação às especificidades de uma nova categoria social - os agricultores familiares (SCHNEIDER, CAZELLA e MATTEI, 2004).

Com o passar dos anos, o Pronaf foi se estruturando e aumentou significativamente seu campo de atuação, sendo que essas alterações se deram além da ampliação dos recursos, contratos e número de agricultores beneficiados. 
Uma importante etapa desse programa foi justamente a incorporação de novas linhas de apoio, seja através da inserção de segmentos até então excluídos pelas políticas agrícolas - como mulheres, jovens, pescadores, indígenas e quilombolas - seja pela inclusão, reconhecimento e legitimação de novas atividades agrícolas e não agrícolas no meio rural - industrialização em escala familiar, turismo rural, agrocombustíveis, etc.

No que diz respeito à agroindústria familiar ${ }^{2}$, em 1998, o Pronaf incorporou uma linha de crédito para investimento denominada Agregação de Renda à Atividade Rural (Pronaf-Agregar), que, em 2003, foi renomeada para PronafAgroindústria $^{3}$. O surgimento desse mecanismo esteve relacionado à expressividade econômica que essa atividade já apresentava nas receitas nacionais em 1996 (aproximadamente 2,5\% do PIB agropecuário e 6\% do PIB gerado pela agricultura familiar), à pressão dos movimentos sociais para o apoio a essas iniciativas (em especial as organizações localizadas no Sul do Brasil) e às dificuldades presentes nas agroindústrias familiares diante da inexistência de uma linha de crédito específica para a atividade.

Esse arcabouço condicionou o desenvolvimento do crédito voltado ao apoio das agroindústrias familiares, sendo que, na maioria dos estados brasileiros, essa era a única fonte disponível para o financiamento dos empreendimentos. Mesmo com a abrangência nacional do Pronaf-Agroindústria e com a sua importância na implementação de atividades diferenciadas dentro da agricultura de base familiar, desconhecem-se estudos que abarquem a trajetória dessa linha de crédito.

O objetivo central deste artigo é analisar a política de crédito rural direcionada às agroindústrias familiares (Pronaf-Agroindústria), trazendo em evidência a constituição, elaboração, implementação e os resultados alcançados. Além disso, é discutido todo o processo de reformulação das condições de acesso ao crédito ao longo dos últimos anos, problematizando as transformações

\footnotetext{
2 Agroindústria familiar se refere às "formas de organização em que a família rural produz, processa e/ou transforma parte de sua produção agrícola e/ou pecuária, visando, sobretudo, à produção de valor de troca que se realiza na comercialização" (MIOR, 2005, p. 191). Essa delimitação tem grande proximidade com o conceito que é utilizado pelas políticas públicas, mostrando uma concordância do uso do termo entre os programas de apoio e os estudos acadêmicos.

3 Além dessa linha de crédito federal, foram implementadas algumas iniciativas na escala estadual destinadas ao apoio das agroindústrias familiares, merecendo destaque o Programa de Verticalização da Pequena Produção Agrícola do Distrito Federal - Prove/DF (1995 a 1998), o Programa de Verticalização da Pequena Produção Agropecuária - Prove-Pantanal/ MS (1999 a 2002), o Programa de Desenvolvimento da Agricultura Familiar Catarinense pela Verticalização da Produção - Desenvolver/SC (1999 a 2001), o Programa da Agroindústria Familiar - PAF/RS (1999 a 2002) e o Programa Fábrica do Agricultor - PR (1999 a 2010).
} 
570 - Política Pública de Agroindustrialização na Agricultura Familiar: Uma Análise do Pronafagroindústria

ocorridas no Pronaf-Agroindústria com a efetivação do Programa Mais Alimentos. É importante destacar que esta última política foi criada de forma emergencial para combater a crise alimentar e reestruturou significativamente algumas linhas do Pronaf.

Para a realização deste trabalho foram utilizados inicialmente os documentos oficiais disponibilizados pelo Pronaf-Agroindústria para entender a proposta da política, seus objetivos e suas premissas. Posteriormente, foram feitas entrevistas semiestruturadas em julho de 2008 com três policy-makers envolvidos na elaboração e gestão dessa linha de crédito com vistas a compreender o seu processo de formulação e implementação. Em seguida, para atingir os resultados nacionais alcançados pelo Pronaf-Agroindústria, foram realizadas consultas em base de dados oficiais buscando identificar o financiamento direcionado às unidades familiares. As informações daí provenientes referem-se tanto ao Pronaf-Agroindústria como ao PronafInvestimento destinado para essa atividade, pois não foi possível obter dados específicos e desagregados.

Além desta parte introdutória, o artigo discute: (i) as motivações para o surgimento e criação da linha de crédito voltada ao apoio das agroindústrias familiares; (ii) o processo de implementação e o foco de intervenção do PronafAgroindústria e(iii) os resultados alcançados por essa modalidade de financiamento. Finalmente, são realizados alguns apontamentos acerca da situação do PronafAgroindústria no contexto atual, a partir de sua trajetória histórica.

\section{Crédito rural para as agroindústrias familiares no Brasil: o Pronaf-Agroindústria}

É expressivo o número de agricultores familiares que passaram a se envolver com a agroindustrialização da produção a partir da baixa rentabilidade das demais atividades exercidas até então dentro da propriedade. Isto significa que as outras fontes de renda, na maior parte dos casos ligadas estritamente à agricultura, não eram mais suficientemente rentáveis para garantir a reprodução familiar. Nesse sentido, a agroindustrialização surge, na maioria dos casos, a partir de um contexto de insatisfação econômica que está geralmente atrelada às frustrações de safra, redução dos preços das commodities e aumento do custo dos insumos (OLIVEIRA, SCHMIDT e SCHMIDT, 2000; OLIVEIRA, PREZOTTO e VOIGT, 2002). Obviamente, nos casos em que são esses os motivos que fazem com que as unidades passem a se interessar pela agroindustrialização, é comum que os agricultores não contem com a quantidade de recursos 
necessários para a construção de infraestrutura básica, compra de equipamentos e até mesmo para a obtenção de capital de giro. Nessa perspectiva, a disponibilidade de linhas de financiamento torna-se indispensável para estimular os investimentos nesse ramo.

\subsection{As motivações para a criação de linhas de crédito para a agroindústria familiar}

A proposição de criar linhas de crédito rural específicas ao apoio das agroindústrias familiares esteve fundamentada na situação que o meio rural brasileiro se deparou ao longo da segunda metade do século XX. Isso porque a agricultura familiar foi vítima de um intenso processo de especialização produtiva que condicionou uma rápida perda de autonomia e a redução da renda desse público, proporcionando um ambiente de crescente vulnerabilidade para essas famílias (WILKINSON, 1999). Nesse contexto, as estratégias de agregação de valor dentro das propriedades começam a ser apontadas como uma importante alternativa para os agricultores, uma vez que possibilita a geração de renda pela agroindustrialização da própria matéria-prima, diminuindo a dependência dos segmentos a montante e a jusante das cadeias produtivas (PREZOTTO, 1999). Isso proporcionou às pequenas agroindústrias um importante papel dentro da agricultura familiar, o que passou a ser defendido no momento de reivindicação das políticas públicas diferenciadas.

Além disso, mais três motivações se apresentaram enquanto elementos determinantes para o surgimento do crédito rural voltado ao apoio das agroindústrias familiares. Primeiramente, cabe destacar a existência do Programa de Verticalização da Pequena Produção Agrícola do Distrito Federal (Prove/DF), que foi implementado em 1995/98 e teve como foco central a criação de empreendimentos de agregação de valor dentro das pequenas propriedades familiares (OLIVEIRA, 2000). O Prove/DF ganhou destaque nacional ao desenvolver ferramentas distintas dos usuais esquemas de intervenção voltados ao meio rural, tornando-se uma política inovadora pelo seu período de atuação, foco de apoio, público-alvo e atividade beneficiada. Essa experiência estimulou a criação de um mecanismo de incentivo às pequenas agroindústrias familiares em termos nacionais, deixando de se ter apenas programas estaduais e municipais.

Um segundo fator a destacar foi a forte demanda dos movimentos sociais pela implementação dessa iniciativa produtiva para o seu público. Os argumentos usados baseavam-se nas afirmações de que a agregação de valor tinha um 
572 - Política Pública de Agroindustrialização na Agricultura Familiar: Uma Análise do Pronafagroindústria

importante papel para a reprodução da agricultura familiar brasileira, uma vez que diminuía a vulnerabilidade social e econômica do grupo doméstico através do aumento da autonomia dos agricultores. A necessidade de uma linha do Pronaf voltada às agroindústrias familiares "estava na pauta da Federação dos Trabalhadores da Agricultura Familiar (Fetraf-Sul), Federação Nacional dos Trabalhadores na Agricultura (Contag), Movimento dos Trabalhadores Rurais Sem-Terra (MST) e Movimento dos Pequenos Agricultores (MPA)" (Gestor do Programa, Entrev. 1). Nesse sentido, a reivindicação de atores sociais paralelos à esfera pública teve peso decisivo na construção do Pronaf-Agroindústria.

Além dos dois pontos já considerados, não se pode deixar de lado um terceiro e último fator, mas nem por isso menos importante, que foi a proliferação de uma série de estudos e pesquisas acadêmicas que apontaram para a importância da agroindustrialização na agricultura familiar e para o desenvolvimento do espaço rural ${ }^{4}$. A maioria dos trabalhos produzidos neste período apresenta seus argumentos pautados fundamentalmente na realidade empírica do Sul do País, até mesmo porque era onde encontravam-se experiências mais consolidadas. Mesmo assim, traziam em sua essência algumas proposições que indicavam a necessidade de iniciativas de agregação de valor em termos nacionais como mecanismo de geração de emprego e renda para os agricultores familiares.

A estes estudos agregaram-se outras vertentes analíticas como pluriatividade, multifuncionalidade e ruralidade, que, mesmo sem defender explicitamente as estratégias de agregação de valor para a agricultura familiar, reconheceram a presença dessas "novas" atividades. Esses referenciais destacam a relevância de pensar o meio rural enquanto um espaço não exclusivamente agrícola, evidenciando a necessidade de criar formas de intervenção para além da produção primária. Como as pequenas agroindústrias desenvolvem tanto a produção de matérias-primas (atividades agrícolas), como o beneficiamento e a industrialização da produção na propriedade (ocupações não agrícolas) até a comercialização do produto final, esse debate acabou incorporando esses empreendimentos familiares em um movimento mais geral de busca por políticas mais amplas e abrangentes para as unidades familiares.

Diante da contribuição desse conjunto de fatores para a implementação de uma linha de crédito voltada às agroindústrias familiares, duas modalidades foram criadas na esfera federal: o Pronaf-Agroindústria e o Pronaf-Agregar. Primeiramente, surgiu em 1998 o "Pronaf-Agroindústria: Integração,

\footnotetext{
4 No Brasil, destacam-se os precursores nesse debate: Azevedo, Colognese e Shikida (2000), Prezotto (1999), Vieira (1998), Wilkinson (1999) e Mior e Wilkinson (1999).
} 
Agroindustrialização e Comercialização da Produção da Agricultura Familiar", em que uma das estratégias de intervenção estava voltada a uma linha de crédito para investimento. Já o Pronaf-Agregação de Renda à Atividade Rural (Pronaf-Agregar) foi criado "no primeiro semestre de 1999 pelo Banco do Brasil, como uma cópia do Pronaf-Agroindústria, se assemelhando muito com ele, o que causou uma série de confusões entre ambas as linhas" (Gestor do Programa, Entrev. 1). Assim, existiam duas linhas de crédito para uma mesma atividade, onde a diferença maior, e que estimulou a consolidação do Pronaf-Agregar, foi a possibilidade de realizar financiamentos individuais, enquanto que no PronafAgroindústria só eram contratados projetos que estivessem estruturados em redes.

Embora com uma proposta enxuta, o Pronaf-Agroindústria não vingou e ficou sem apoiar nenhum empreendimento diante de uma série de mudanças em sua estrutura, incluindo sua migração do Ministério da Agricultura, Pecuária e Abastecimento (Mapa) para o Ministério do Desenvolvimento Agrário (MDA), em 1999. Além disso, houve "uma clara demonstração de falta de interesse dos agentes financeiros em implementar o Pronaf-Agroindústria" (MIOR, 2005, p. 167). Esse fato decorre da próxima relação existente entre o Banco do Brasil e o Pronaf-Agregar, além de esta linha ser mais flexível e aceitar os projetos que eram individuais. Entretanto, até os financiamentos que estavam estruturados no formato de redes ficaram sem acessar o Pronaf-Agroindústria, como foi o caso de dois projetos em Santa Catarina (SCHMIDT, 2000).

Desde 1999 até o final de 2002, a linha que aplicou recursos para as agroindústrias familiares foi o Pronaf-Agregar, enquanto que o crédito via PronafAgroindústria não chegou a ser operacionalizado. Em 2003, com o início do governo Lula, o Pronaf-Agregar foi mantido, mas renomeado, passando a se chamar Pronaf-Agroindústria. Embora essa linha tenha uma perspectiva de rede como a primeira, agora é possível o financiamento de projetos individuais. Isso mostra o reconhecimento dos formuladores dessas políticas públicas de que a opção por agroindústrias familiares coletivas é importante, mas que ainda é remota a possibilidade de estruturar este tipo de empreendimento em termos nacionais, o que tornaria esta orientação coletivista excludente e limitaria o público beneficiado, como argumentou Raupp (2005).

A partir de 2003, o Pronaf-Agroindústria passa a compor o Programa de Agroindustrialização da Agricultura Familiar, deixando de ser uma estratégia isolada porque passa a ser implementada em conjunto com outras iniciativas de fundamental importância para a viabilização das agroindústrias no meio rural. Além dos financiamentos, foi articulada uma série de medidas no que se refere a legislações, capacitação, adaptação de tecnologias e acesso aos mercados. 
574 - Política Pública de Agroindustrialização na Agricultura Familiar: Uma Análise do Pronafagroindústria

\subsection{Foco de intervenção e implementação do Pronaf-Agroindústria}

De 2003 em diante, o Pronaf-Agroindústria foi agregado ao Programa de Agroindustrialização da Agricultura Familiar, voltando-se fundamentalmente para os investimentos, inclusive em infraestrutura, que visem beneficiamento, processamento e comercialização da produção. Nesse sentido, essa linha de crédito se direciona à implantação de pequenas e médias agroindústrias, isoladas ou em forma de rede; à implantação de unidades centrais de apoio gerencial e à ampliação, recuperação e modernização de unidades já instaladas (Brasil, 2004). O público principal do Pronaf-Agroindústria são os agricultores familiares enquadrados no Pronaf conforme os grupos A/C, B, C, D e E E $^{5}$. Além desses, podem acessar os recursos dessa linha as cooperativas, associações ou outras formas jurídicas, desde que enquadradas como agricultores familiares de acordo com o Manual de Crédito Rural (MCR).

Os principais bancos que realizam os financiamentos do PronafAgroindústria são o Banco do Brasil (BB), Banco Nacional de Desenvolvimento Econômico e Social (BNDES), Banco da Amazônia (Basa) e Banco do Nordeste. Essas e outras instituições financeiras operam com recursos do Fundo de Amparo ao Trabalhador (FAT), que é a principal fonte dos recursos acessados por essa linha do Pronaf. Além do FAT, existe a possibilidade de solicitar recursos para os agricultores que moram nas regiões Norte, Nordeste e Centro-Oeste, via Fundos Constitucionais de Financiamento. Nesse caso, o prazo de reembolso pode ser de até 16 anos, desde que o projeto ateste essa necessidade, enquanto que nas demais fontes o limite é de oito anos, detendo de três a cinco anos de carência.

Mesmo com linha de crédito específica para a agroindústria familiar, muitos agricultores têm acessado recursos via Pronaf-Mulher, Pronaf-Jovem e, principalmente, Pronaf-Investimento (WESZ JUNIOR, 2009). Conforme os gestores do programa, isso ocorre porque o Pronaf-Agroindústria, quando demandado inicialmente, não exclui a possibilidade de acessar outro financiamento pelo Pronaf-Investimento. Entretanto, quando se recorre primeiramente ao Pronaf-Investimento para a agroindústria, não é mais possível acessar algum implemento agrícola porque esta linha não permite o duplo acesso. Nesse sentido,

\footnotetext{
5 A partir do Plano Safra 2008/09 os grupos de agricultores C, D e E do Pronaf deixam de existir e as condições de financiamento passam a ser estabelecidas pelo valor dos recursos solicitados.
} 
tem uma tendência dos bancos em direcionar [o financiamento da agroindústria] para a linha Investimento para evitar o risco de um endividamento dos produtores, porque um agricultor do grupo $\mathrm{D}$ poderia tirar $\mathrm{R} \$ 36 \mathrm{mil}$, sendo $\mathrm{R} \$ 18$ mil pelo Agroindústria e mais $\mathrm{R} \$ 18$ mil pelo Investimento. Mas se o agente financeiro colocar o primeiro financiamento no Investimento, ai já não se pode acessar o Agroindústria e o máximo acessado por agricultor fica $\mathrm{R} \$$ 18 mil e não mais $\mathrm{R} \$ 36$ mil. Portanto, se ele constrói uma agroindústria de laticínios com o Pronaf-Investimento e vai ao mesmo tempo querer comprar algumas matrizes para aumentar a produção de matéria-prima, ele não vai conseguir, só conseguiria outros financiamentos se acessasse inicialmente o Pronaf-Agroindústria (Gestor do Programa, Entrev. 2).

Desde o início do programa até o Plano Safra 2008/09, é visível uma alteração nas condições de financiamento do Pronaf-Agroindústria, em especial no que diz respeito às taxas de juros, às exigências de enquadramento no caso das cooperativas e ao montante dos financiamentos coletivos. O limite de pagamento e o período de carência não sofreram alterações a partir de 2003, até porque são variáveis com características mais constantes.

As taxas de juros ao longo desses 10 anos apresentaram significativa redução em todos os grupos de agricultores. Ao considerar o caso dos produtores C e D em 1998, quando a linha era denominada Pronaf-Agregar, é possível perceber uma diminuição expressiva da taxa de juros. No primeiro caso, que engloba os agricultores com renda bruta anual familiar de $R \$ 4$ mil até $R \$ 18$ mil (grupo C), a taxa de juros caiu de 5,75\% para $1 \%$. Algo semelhante aconteceu com o grupo D: agricultores que possuem renda bruta anual familiar entre $\mathrm{R} \$$ 18 mil e $\mathrm{R} \$ 50$ mil, houve queda de $5,75 \%$ para $2 \%$. Os grupos B e A/C, assim como o E, que passaram a compor o Plano Safra a partir do ano agrícola de 2003/04, também apresentaram reduções progressivas durante todo o período. Somente o grupo E teve aumento nas taxas de juros em 2007/08 de 3\% para $5,5 \%$, mas foi reduzido para $2 \%$ um ano depois (Tabela 1 ).

Além da diminuição generalizada das taxas de juros no PronafAgroindústria, chama atenção a diferenciação por grupo de agricultor, o que não acontecia até o Plano Safra de 2007/08, quando o grupo E teve a taxa de juros elevada de $3 \%$ para $5,5 \%$ enquanto os demais tiveram redução de $2 \%$. No ano agrícola 2008/09, a distinção entre os valores das taxas de juros é reduzida, 
576 - Política Pública de Agroindustrialização na Agricultura Familiar: Uma Análise do Pronafagroindústria

mas permanece uma diferenciação dos grupos D e E (2\%) em relação aos demais (1\%). Isso conduz a uma percepção de que mesmo a agroindústria familiar sendo tratada como alternativa de renda para todos os estratos de agricultores, no momento do financiamento, ela precisa considerar as especificidades dos beneficiários nas suas condições de quitação do empréstimo. Nesse sentido, os agricultores que acessarem um financiamento com valores mais baixos, até pela sua menor capacidade de pagamento, obtém taxas de juros mais condizentes com suas possibilidades de honrar com o compromisso. Por outro lado, os agricultores com projetos de maior valor teriam juros mais elevados, porque se subentende que investimentos maiores obtêm melhores condições para realizar o pagamento.

Tabela 1. Taxa de juro (a.a.) no Pronaf-Agroindústria conforme o período do contrato e os grupos de agricultores

\begin{tabular}{c|c|c|c|c|c|c}
\hline \multirow{2}{*}{$\begin{array}{c}\text { Grupos do } \\
\text { Pronaf }\end{array}$} & $\begin{array}{c}\text { (ao ano) } \\
1998 /\end{array}$ & $2000 /$ & $2003 /$ & $2005 /$ & $2007 /$ & $2008 /$ \\
& 2000 & 2003 & 2005 & 2007 & 2008 & $2009 * *$ \\
\hline B & - & - & 4,0 & 3,0 & 2,0 & 1,0 \\
A/C & - & - & 4,0 & 3,0 & 2,0 & 1,0 \\
C & 5,75 & 4,0 & 4,0 & 3,0 & 2,0 & 1,0 \\
D & 5,75 & 4,0 & 4,0 & 3,0 & 2,0 & 2,0 \\
E & - & - & 4,0 & 3,0 & 5,5 & 2,0 \\
\hline
\end{tabular}

Fonte: Plano Safra (1998/99 até 2008/09).

Organizado pelo autor.

* Até o Plano Safra de 2002/03 essa linha era denominada Pronaf-Agregar.

** A partir do Plano Safra 2008/09 deixaram de existir os grupos de agricultores C, D e E, e agora a taxa de juros se dá pelo montante do financiamento (até $\mathrm{R} \$ 7$ mil é $1 \%$ a.a.; de $\mathrm{R} \$ 7$ mil a $\mathrm{R} \$ 18$ mil é $2 \%$ a.a.). Para manter a comparabilidade desse quadro com os demais anos, nos baseamos no teto dos financiamentos da linha Investimento, onde somente os grupos D e E poderiam acessar valores acima de $\mathrm{R} \$ 7 \mathrm{mil}$.

Essa redução dos juros não tem acontecido somente na linha Agroindústria, mas em todo o Pronaf. No início do programa, em 1996, a linha voltada para o Custeio Agropecuário tinha uma taxa de $9 \%$ a.a. e foi caindo ano a ano, estando 
a 1,5\% a.a no Plano Safra de 2008/09 (COPETTI, 2008). Além de ser uma opção política a redução da taxa de juros, há forte estímulo a partir da estabilização econômica que faz com que se mantenha uma tranquilidade maior em diminuir as taxas de juros sem o risco de grandes oscilações entre o momento de assinatura do contrato e seu pagamento.

Mesmo assim, "as liberações de recursos para os agricultores têm, em contrapartida, um custo para o Tesouro, dado pela necessidade de equalizar com recursos do Orçamento a diferença entre os juros cobrados aos beneficiários e a taxa SELIC" (GUANZIROLI, 2006, p. 3). Conforme o autor, o montante destinado a esse fim tem sido declinante - pois o valor liberado para equalizar juros e rebates de adimplência caiu de 60\% em 2002 para $28 \%$ em 2005 - mas ainda é alto se comparado com outras políticas agrícolas. Nesse sentido, a redução da taxa de juros apresenta um aumento do subsídio aos agricultores familiares e, consequentemente, um custo maior para o Tesouro.

Além da redução da taxa de juros e do aumento do custo disso para o Tesouro, o público beneficiário do Pronaf-Agroindústria também se alterou substancialmente. Entre os anos agrícolas de 2003/04 e 2007/08, o foco da linha de crédito eram os agricultores familiares enquadrados no Pronaf, além de cooperativas, associações ou outras formas jurídicas constituídas em $90 \%$ ou mais de agricultores familiares, sendo que esses precisavam comprovar no projeto técnico que mais de $70 \%$ da matéria-prima era produzida pela própria unidade familiar. No último Plano Safra (2008/09), com a entrada do Programa Mais Alimentos ${ }^{6}$, as condições de enquadramento nos casos que envolvem a cadeia produtiva do leite se alteraram substancialmente. Com as mudanças, no caso dos contratos coletivos direcionados para a cadeia dos lácteos, é necessário ter a sua estrutura social formada por $70 \%$ de agricultores familiares, enquanto que anteriormente era $90 \%$, e a participação dos produtores na produção leiteira precisa ser de $55 \%$, em vez de $70 \%$, como nos anos antecedentes e nas demais cadeias produtivas.

Concomitantemente ao alastramento das condições de financiamento, teve-se aumento no valor dos recursos a serem acessados coletivamente. No período de 1998 a 2003, o teto dos contratos não poderia ultrapassar $\mathrm{R} \$ 600$

\footnotetext{
${ }_{6}$ O Mais Alimentos é uma política criada em 2008, implementada de forma combinada com o Plano Safra da Agricultura Familiar, onde foi proposta uma série de iniciativas na tentativa de reduzir o impacto da "crise dos alimentos". Dentro do Pronaf-Agroindústria, o Mais Alimentos está direcionado ao processamento e industrialização do leite e derivados nas cooperativas.
} 
578 - Política Pública de Agroindustrialização na Agricultura Familiar: Uma Análise do Pronafagroindústria

mil. A partir de então aconteceram algumas mudanças nas normas, estabelecendo-se que os contratos grupais não poderiam ser constituídos por mais de 40 pessoas e que o limite de cada agricultor no financiamento seria de $\mathrm{R} \$ 18$ mil - o teto do financiamento coletivo poderia chegar, no máximo, a $\mathrm{R} \$$ 720 mil (Tabela 2).

Com a introdução do Mais Alimentos em 2008, no caso do processamento e industrialização do leite e derivados em cooperativas, pode-se chegar a um montante de até $\mathrm{R} \$ 25$ milhões nos contratos coletivos, enquanto que o limite individual é de até $\mathrm{R} \$ 28$ mil por sócio, segundo o Plano Safra 2008/09. Se comparar o limite de agricultores por projeto coletivo, é perceptível uma brusca alteração: até o ano agrícola de 2007/08, era possível, no máximo, 40 pessoas por contrato e, no ano seguinte, esse valor foi para quase 900 agricultores (aumento de 2.231\%). Assim, fica visível uma grande mudança dentro da linha Pronaf-Agroindústria no cenário recente, aparecendo com clareza o propósito de apoiar, também, as grandes agroindústrias.

Além disso, até 2007/08, o teto do financiamento coletivo era o mesmo para todos os agricultores, independente da sua renda (a renda é o fator delimitador dos grupos). Isso acabava oportunizando a construção de empreendimentos coletivos pelo grupo $\mathrm{C}$ nos mesmos valores do grupo $\mathrm{E}$. Obviamente, isso poderia causar um desconforto por parte dos agentes financeiros pelo receio de endividamento dos produtores com menores condições de pagamento, mas possibilitava a oportunidade de investimentos de forma equiparada. Mais recentemente, reduziu-se o valor para os contratos coletivos ligados aos agricultores mais descapitalizados e aumentou-se, de forma repentina, a disponibilidade para aqueles que estão envolvidos com a industrialização de leite e derivados. 
Tabela 2. Teto dos financiamentos coletivos da linha Pronaf-Agroindústria conforme o período dos contratos e os grupos de agricultores

\begin{tabular}{c|c|c|r}
\hline \multirow{2}{*}{ Grupo do Pronaf } & \multicolumn{2}{|c}{ Teto do financiamento coletivo para o Pronaf-Agroindústria (R\$) } \\
& $1998 / 99$ até & $2003 / 04$ até & \\
& $2002 / 03^{*}$ & $2007 / 08$ & $2008 / 09^{* *}$ \\
\hline B & - & $720.000,00$ & $500.000,00$ \\
A/C & - & $720.000,00$ & $500.000,00$ \\
C & $600.000,00$ & $720.000,00$ & $10.000 .000,00$ \\
D & $600.000,00$ & $720.000,00$ & $10.000 .000,00$ \\
E & - & $720.000,00$ & $25.000 .000,00$ \\
\hline
\end{tabular}

Fonte: Plano Safra (1998/1999 até 2008/2009).

* Até o Plano Safra de 2002/03, essa linha era denominada Pronaf-Agregar.

*** Vide nota similar na Tabela 01.

Essa flexibilização tem se tornado emblemática, pois toda a estrutura da linha de crédito estava voltada para as pequenas agroindústrias e, desde então, esse mecanismo de apoio ganhou uma conotação distinta ao histórico do PronafAgroindústria. Nesse sentido, parece ter se instaurado uma dualidade entre a opção de apoiar as grandes cooperativas de beneficiamento da produção leiteira ou continuar incentivando as pequenas agroindústrias que funcionam em regime estritamente familiar. Além de decidir os rumos que esta linha de crédito irá seguir, essa discussão perpassa pela própria visão de desenvolvimento pensada para a agricultura familiar na atualidade, isto é, a construção de alternativas autônomas (pequenas agroindústrias no interior da propriedade) ou empreendimentos maiores fora do estabelecimento agropecuário (grandes cooperativas de produtores).

\subsection{Resultados alcançados pelo crédito rural}

A coleta dos dados sobre o número de financiamentos direcionados para as unidades familiares de beneficiamento da produção é, como já foi alertado anteriormente, proveniente tanto do Pronaf-Agroindústria como do PronafInvestimento destinado para essa atividade. Embora não seja possível estabelecer uma diferenciação do número de contratos por linha de financiamento, como 
580 - Política Pública de Agroindustrialização na Agricultura Familiar: Uma Análise do Pronafagroindústria

seria o ideal, pode-se analisar o montante dos recursos entre os anos de 2003 a $2006^{7}$.

É importante destacar que as informações sobre os financiamentos são coletadas pelos policy-makers a partir dos dados do

Banco Central sobre o Pronaf-Agroindústria e PronafInvestimento, [sendo que] nesse último caso é depurado aquilo que é equipamento e que tem características de industrialização e beneficiamento. Além disso, se faz um mapeamento dos recursos aplicados pelos parceiros, no caso Cresol, Emater, etc. para ver se fecha com os outros dados (Gestor do Programa, Entrev. 2).

Infelizmente, não existe discriminação entre as linhas do Pronaf, o que impossibilita análise mais minuciosa acerca da distribuição do crédito por grupo de agricultores, regiões geográficas e tipo de atividade. Os dados disponíveis se restringem ao número de agroindústrias e famílias apoiadas, além do montante de recursos gastos com o crédito.

As metas estabelecidas no documento referencial para os quatro anos iniciais do Programa de Agroindustrialização da Agricultura Familiar previam a disponibilização de crédito através do Pronaf para 7.700 agroindústrias (Brasil, 2004). Os resultados ficaram próximos das expectativas iniciais, pois foram financiados 7.485 empreendimentos nesse período, o que representa o cumprimento de 97\% das metas (Figura 1). Entre 2003 e 2006, o número de agroindústrias apoiadas foi crescente, destacando a difusão do crédito nessa atividade, assim como o potencial desse mecanismo para abranger cada vez mais unidades. O número de empreendimentos apoiados em 2003 esteve abaixo dos demais anos porque foi nesse momento que se efetivou uma série de mudanças para a reestruturação da linha Pronaf-Agroindústria, incluindo a sua própria renomeação. Em 2004, as expectativas para esse período foram superadas, atingindo praticamente 700 unidades a mais do que as previstas. Em 2005 e 2006, as metas estipuladas não foram alcançadas, ficando $20 \%$ e $10 \%$ abaixo das esperadas, respectivamente.

\footnotetext{
7 O período de análise dos dados do Pronaf-Agroindústria é iniciado em 2003, tendo em vista que não existem informações disponíveis sobre os anos anteriores, quando a linha ainda era denominada de Pronaf-Agregar (1998 até 2002). Da mesma forma, não foi possível obter dados dos contratos efetivados após 2006.
} 


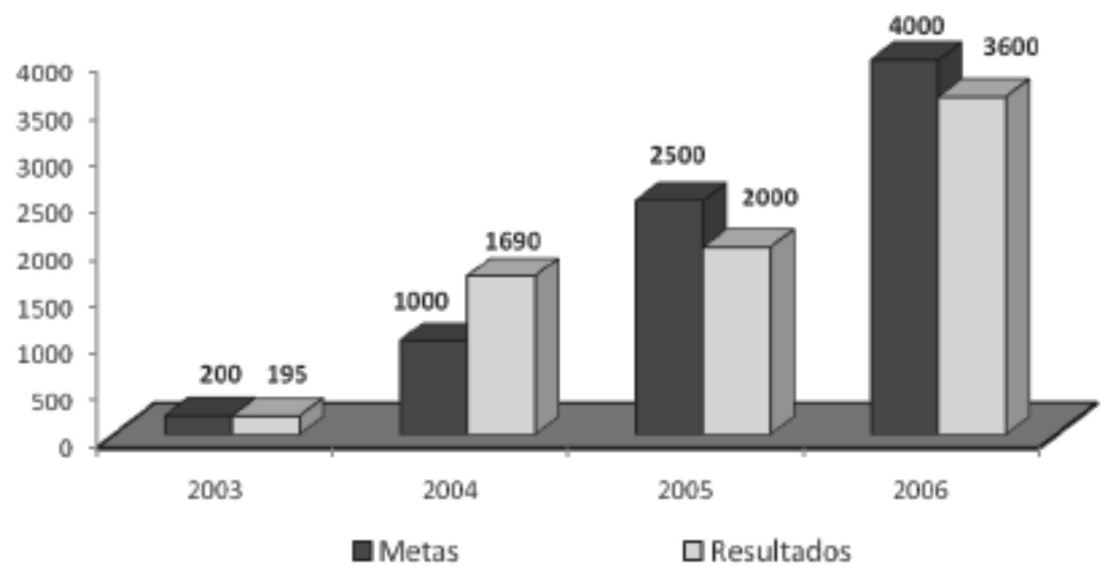

Figura 1. Número de agroindústrias familiares atingidas pelo Pronaf (Agroindústria e Investimento) no Brasil (metas estabelecidas e resultados alcançados)

Fonte: Brasil (2007).

Estava prevista uma participação média no acesso ao crédito de 10 famílias por agroindústria, o que representava a inclusão de 77 mil famílias no total entre 2003 e 2006 (Brasil, 2004). Contudo, foram atingidas pouco mais de 56 mil famílias, o que representa uma média de 7,5 famílias por empreendimento. Diante disso, pode-se dizer que se cumpriu $73 \%$ das metas nessa variável, mostrando a considerável participação de pequenas agroindústrias associativas no programa, onde a gestão não acontece somente por um único grupo doméstico. A Figura 2 mostra que, tanto em 2003 como em 2004, houve grande proximidade entre as metas estabelecidas e os resultados alcançados no que se refere ao número de famílias atingidas pelo crédito rural. Já nos anos de 2005 e 2006, houve distanciamento da previsão inicial, cobrindo de $60 \%$ a $70 \%$ das metas estipuladas no documento referencial. 
582 - Política Pública de Agroindustrialização na Agricultura Familiar: Uma Análise do Pronafagroindústria

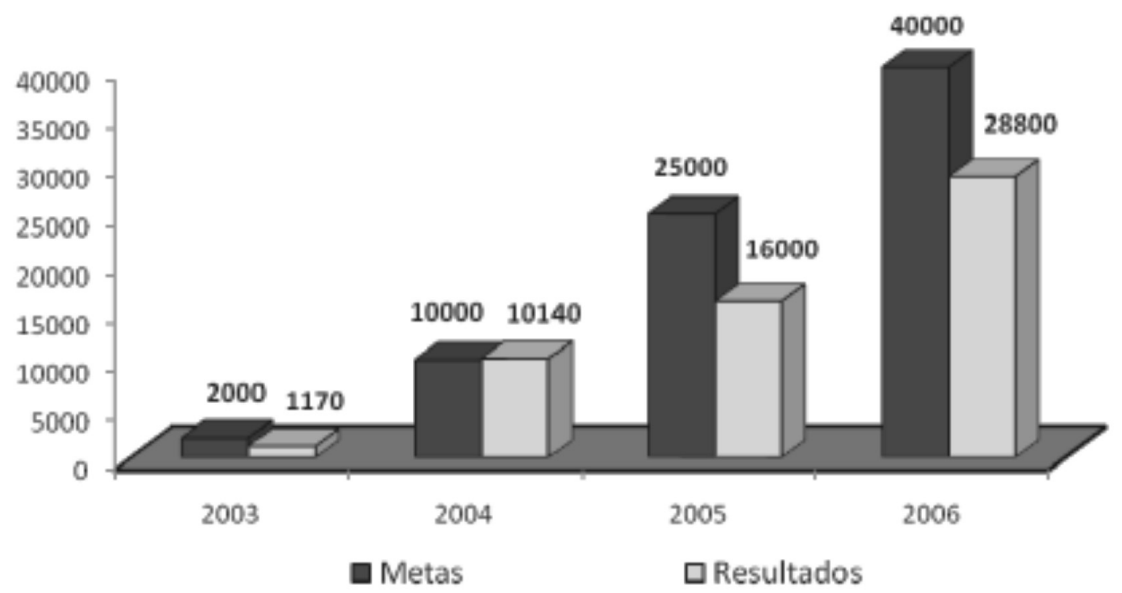

Figura 2. Número de famílias atingidas pelo Pronaf (Agroindústria e Investimento) nos financiamentos direcionados às agroindústrias (metas estabelecidas e resultados alcançados)

Fonte: Brasil (2007).

De todo modo, mesmo com uma estimativa inicial maior do que os resultados efetivamente alcançados sobre o número médio de famílias por unidade, é importante ressaltar que, ao longo dos quatro anos analisados, sempre ocorreu uma média superior a seis famílias por agroindústria que acessaram o crédito rural para a atividade. Por um lado, esse resultado vai ao encontro do que, para alguns autores, é destacado como uma forte relação deste tipo de empreendimento com as formas de organização associativas e cooperativas, uma vez que condiciona a otimização dos maquinários, instalações e equipamentos, racionalizando recursos pela diminuição da capacidade ociosa (PREZOTTO, 2002; MIOR, 2005). Por outro lado, o elevado número de famílias por agroindústrias chama atenção sobre uma necessidade que é imposta pelo crédito, onde os agricultores precisam se reunir em grupos para acessarem recursos maiores que $R \$ 18$ mil, tendo em vista que esse montante individual não é suficiente para que se construa uma agroindústria dentro dos padrões necessários estabelecidos pelo marco legal. Em suma, a participação de mais de uma família nas agroindústrias pode, de fato, possuir importante papel para a competitividade dos empreendimentos, mas foi condicionada também pelas condições do financiamento entre 2003 e 2006. 
A previsão inicial dos recursos aplicados no crédito rural para o investimento das agroindústrias familiares era de $\mathrm{R} \$ 1,155$ bilhão, estimando gasto próximo dos $\mathrm{R} \$ 150$ mil por financiamento/empreendimento (Brasil, 2004). Os resultados, entretanto, apontaram para uma falsa pressuposição, uma vez que se gastou com esse fim somente $R \$ 239$ milhões (20,7\% das metas), ou seja, a média dos valores dos projetos por agroindústria foi próximo aos $\mathrm{R} \$ 32$ mil, mostrando-se muito abaixo das expectativas iniciais. Para além de uma frustração, esses dados mostram a alta capacidade de se criar pequenas unidades de beneficiamento no meio rural sem a necessidade de desembolsar grandes quantidades de recursos. Isso pode ser visto nas linhas de crédito em análise, já que foram atingidas $97,2 \%$ das metas para as agroindústrias e $73 \%$ das estimativas iniciais em termos de famílias beneficiadas, utilizando somente $20 \%$ do montante de recursos disponíveis. Nesse sentido, pode-se apontar para uma otimização dos recursos diante da formação de empreendimentos descentralizados, geridos pelos investidores e voltados para a atividade de agregar valor. A Figura 3 mostra o desvirtuamento entre as metas estabelecidas e os resultados obtidos no montante de recursos aplicados com o crédito rural para investimento nas agroindústrias familiares. Somente em 2003 se alcançou mais de $50 \%$ das previsões estipuladas. Nos demais anos, a média ficou em torno de $20 \%$.

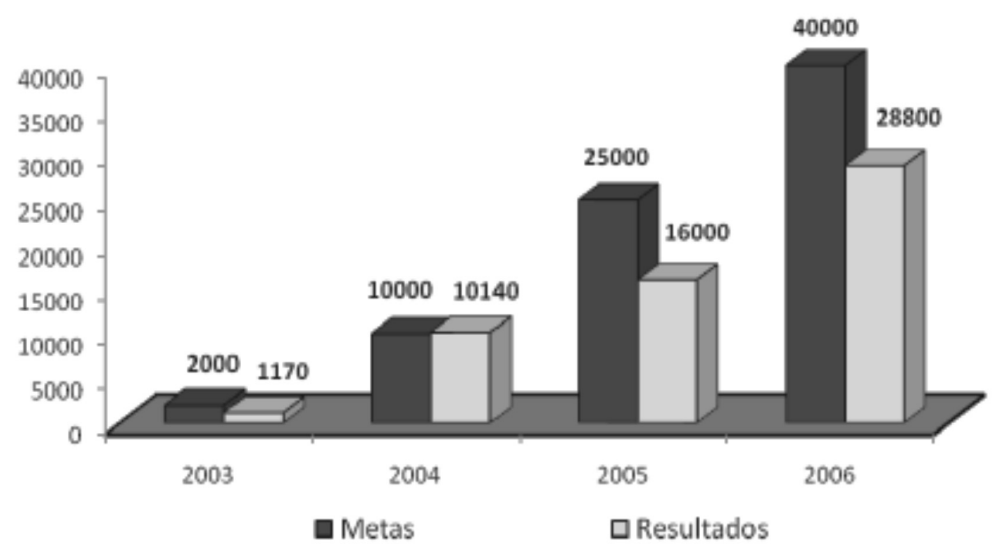

Figura 3. Montante de recursos aplicados pelo Pronaf (Agroindústria e Investimento) no apoio às agroindústrias familiares - metas estabelecidas e resultados alcançados $(\mathrm{R} \$ 1.000,00)$

Fonte: Brasil (2007). 
584 - Política Pública de Agroindustrialização na Agricultura Familiar: Uma Análise do Pronafagroindústria

Essa distorção entre as expectativas e os resultados se deu, portanto, pela percepção dos gestores do programa de que os valores médios dos contratos seriam de $R \$ 150$ mil, enquanto que, na realidade, esse dado ficou quatro vezes abaixo do previsto. Conforme pesquisa realizada por Wesz Junior (2009) em 10 empreendimentos que acessaram o Pronaf-Agroindústria na microrregião de Cerro Largo/RS, os baixos valores médios dos contratos ( $\mathrm{R} \$ 27.475,42)$ estavam atrelados a uma multiplicidade de fatores, cabendo destacar:

i) o acesso a outras linhas do Pronaf (todos os agricultores pesquisados haviam obtido crédito nas modalidades de custeio), o que limita o teto dos contratos a serem financiados pelas agências bancárias;

ii) o receio de endividamento por parte dos beneficiários, o que provoca nos agricultores familiares uma cautela maior no momento de financiar a agroindústria, demandando contratos de menor valor;

iii) a aplicação de recursos próprios (ou emprestado de vizinhos e/ou parentes) na agroindústria, que muitas vezes é investido em paralelo às rubricas adquiridas junto ao Pronaf;

iv) o majoritário acesso dos agricultores familiares com condições financeiras intermediárias (Grupos C e D), os quais não possuem um limite de crédito elevado nos bancos, impedindo a provação de projetos mais expressivos orçamentariamente;

v) a presença de políticas municipais, estaduais e federais simultâneas ao Pronaf, que permitem ao agricultor acessar outros recursos paralelos para as agroindústrias, muitos inclusive "a fundo perdido", isto é, sem necessidade de pagamento;

vi) o expressivo número de investimentos em agroindústrias informais e que apresentam infraestrutra prévia, as quais necessitam de menos recursos aplicados por que geralmente se tratam de readequações das instalações;

Embora sejam considerações específicas de um dado contexto geográfico (microrregião de Cerro Largo/RS), acredita-se que essas mesmas motivações estão presentes em todo Brasil e acabam justificando o baixo valor médio dos contratos do Pronaf voltado às agroindústrias familiares.

Mesmo abaixo das metas previstas, o montante de crédito rural aplicado para investimento na agroindústria familiar via Pronaf foi crescente a partir de 2003, aumentando a ritmo maior que o total de recursos aplicado pelo Pronaf como um todo (Figura 4). Ao longo de 2003 a 2006, os valores destinados às agroindústrias quintuplicaram, enquanto que o Pronaf total dobrou a sua mobilização de recursos. A partir daí, pode-se ver que o apoio direcionado ao 
ramo do beneficiamento da produção é uma atividade com alto potencial de expansão e que apresenta uma demanda reprimida, enquanto que as demais linhas, em especial as voltadas para o custeio da produção primária, por já ter uma trajetória de políticas na área, acabaram ampliando-se em ritmo significativamente menor.

No caso das atividades agrícolas, por ser um setor tradicional no meio rural, o potencial de expansão do crédito é mais reduzido, uma vez que já se está em um patamar elevado de abrangência. Quando ocorre um aumento nos recursos investidos, isso acontece basicamente por dois motivos: i) acréscimo no valor do contrato, fazendo com que o mesmo agricultor adquira mais recursos pelo mesmo projeto; ii) ampliação do público atingido que já estava envolvido na atividade e que passa, em seguida, a disponibilizar de crédito para seus cultivos, utilizando-o para o melhoramento. Nesse sentido, o crédito para a agricultura cresce onde essa atividade já está estabelecida, tendo uma função muito mais de intensificação e qualificação deste ramo produtivo.

No caso da agroindústria, o aumento do montante de recursos tem acontecido de forma diferenciada. Embora haja agricultores que já estavam na atividade e que usam o crédito para melhorar as condições de produção, para muitos, o acesso ao financiamento representa a possibilidade de construir o empreendimento. Isso porque, mesmo para quem já tem uma produção beneficiada para o seu autoconsumo, no momento em que passa a comercializar o produto industrializado, são necessários investimentos em novas estruturas e na qualificação do produto, inclusive quando a produção se mantém informal. Por isso, é comum uma rápida ampliação dos recursos dado que muito agricultores não estavam na atividade, mas que passam a se inserir nessa produção a partir da disponibilidade de uma linha de crédito específica. Ademais, a flexibilização das condições de financiamento se apresentou cada vez mais atrativa para o acesso às linhas de crédito. 
586 - Política Pública de Agroindustrialização na Agricultura Familiar: Uma Análise do Pronafagroindústria

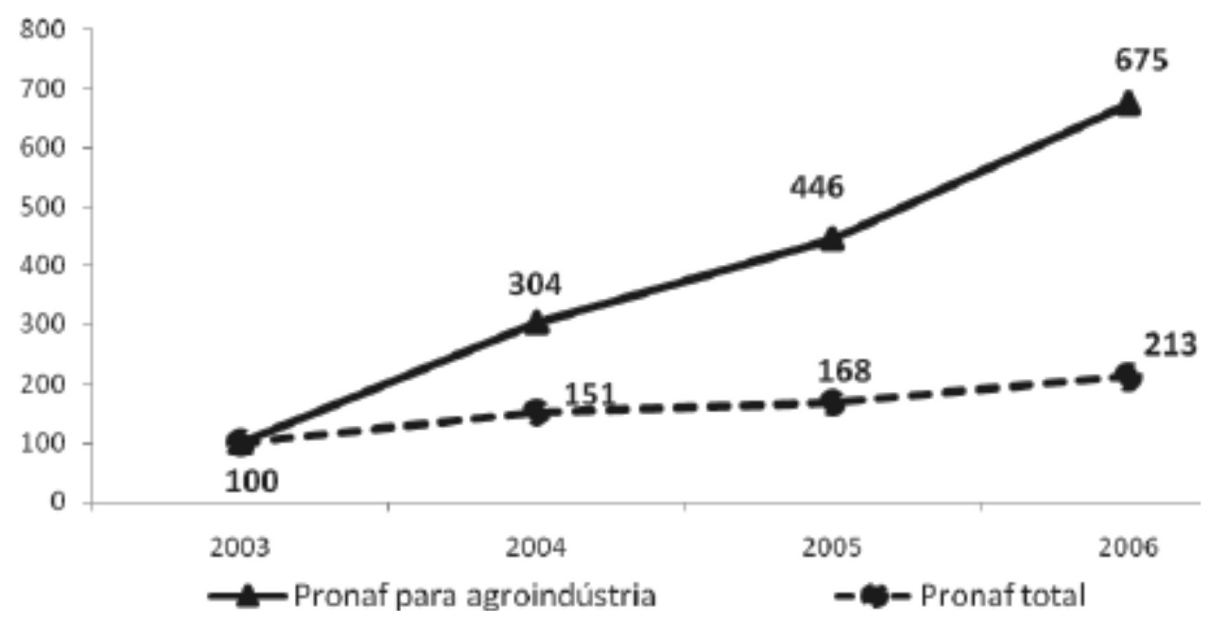

Figura 4. Montante de recursos aplicados nas agroindústrias familiares via Pronaf e o total de crédito rural aplicado pelo Pronaf $(2003=100)$ Fonte: Brasil (2007) e Bacen, Bancoob, Bansicredi, Basa, BB, BN e BNDES (2007).

Em 2003, o crédito rural aplicado na agroindústria familiar ocupou 0,4\% dos recursos disponibilizados por todo o Pronaf. Em 2004, o percentual subiu para $0,8 \%$; em 2005, alcançou $1,1 \%$ e, em 2006 , chegou a 1,3\%. No início, "se tinha a meta de encerrar 2006 com $4 \%$ do montante de recursos aplicados em todo o Pronaf, mas o ritmo de crescimento do Pronaf foi muito alto também, [então] ao manter próximo de 1\% está muito bom" (Gestor do Programa, Entrev. 1). Mesmo que esses percentuais não se mostrem muito representativos, é necessário reconhecer que a agroindústria familiar é uma atividade recente do ponto de vista da intervenção estatal na maioria dos estados brasileiros, enquanto que os cultivos agrícolas e as criações pecuárias já têm uma longa trajetória. Entretanto, ressalta-se a presença de uma demanda reprimida e a possibilidade de ampliação dos recursos em ritmo acima das demais atividades apoiadas pelo Pronaf, como foi visto na Figura 4.

Embora não se tenha dados precisos sobre qual grupo de agricultores tem acessado mais comumente o crédito para as agroindústrias familiares, pode-se perceber a partir dos gestores da política que a participação 
do grupo B é quase insignificante, pois não chega a $1 \%$ [do total]. O grupo C já começa ser significativo e os grupos D e E são os grandes beneficiários do crédito, não por ser o público mais capitalizado, mas por ser um grupo de agricultores que já tem um acesso maior às políticas, especialmente de assistência técnica e capacitação, tendo assim uma formação maior. [Nesses casos] as informações estão mais próximas ejá se tem trabalhado com a produção de matéria-prima, o que acaba influenciando para que os grupos D e E sejam os maiores aplicadores em agroindústria (Gestor do Programa, Entrev. 3).

Além da reduzida presença de agricultores com rendas de até $\mathrm{R} \$ 18 \mathrm{mil}$ (grupos B e C), pode-se perceber a baixíssima participação no acesso ao crédito para a construção de agroindústrias familiares nos assentamentos rurais, já que

não foi apoiado quase nada nesses casos [...] Isso que na concepção do programa se acreditava que o lugar onde iria estourar seria nos assentamentos, porque era o lugar mais fácil para se fazer uma rede de agroindústrias [...] estão localizados em proximidade, já tem uma base organizacional, tem uma base produtiva... Mas isso era só uma idéia, porque na prática não aconteceu (Gestor do Programa, Entrev. 1).

Embora não se tenha elementos suficientes para detalhar os motivos do menor acesso ao crédito por alguns grupos do Pronaf (B e C) e em alguns estratos sociais (assentamentos rurais), tornam-se úteis as afirmações de Raupp (2005) e Guimarães e Silveira (2007) sobre o "privilégio" dos financiamentos para alguns agricultores. Para esses autores, que abordaram especificamente o Programa de Agroindústria Familiar no Rio Grande do Sul (PAF/RS), a política atingiu especialmente as agroindústrias com trajetória de vários anos e os agricultores com um certo grau de capitalização, infraestrutura e com boa clareza de suas demandas e dos canais de encaminhamento dos projetos do programa (já haviam acessado anteriormente crédito rural, possuíam assistência técnica, participavam de sindicatos, cooperativas e associações, etc.). Embora essas declarações pareçam condizentes com o contexto analisado, não é pertinente estendê-las sem um detalhamento maior de dados empíricos. 
588 - Política Pública de Agroindustrialização na Agricultura Familiar: Uma Análise do Pronafagroindústria

O que os dados permitem afirmar até aqui é que entre os anos 2003 e 2006 o crédito rural direcionado às agroindústrias familiares obteve importantes resultados, apontando para um aumento no número de financiamentos para essa atividade. Destaca-se a presença de empreendimentos viabilizados por investimentos próximos dos $\mathrm{R} \$ 30$ mil por unidade, onde a gestão é efetivada por seis a oito famílias de agricultores, em média. Sem o propósito de traçar um perfil das agroindústrias apoiadas, esses resultados apontam que a política direcionou seu foco, até 2006, para as iniciativas formadas predominantemente por pequenos empreendimentos rurais, mantidos por grupos de famílias de agricultores e com baixas despesas com os financiamentos.

Entretanto, as mudanças no Pronaf-Agroindústria em 2008/09, por meio do Programa Mais Alimentos, proporcionaram uma reorientação nos rumos tomados por essa linha de crédito, como já foi apontado acima, baseando-se nas condições de financiamento. Como a alteração é recente, isso impossibilita analise mais aprofundada sobre a intensidade das mudanças, cabendo-nos indicar apenas tendências da política pública em análise. Nesse sentido, algumas questões já podem ser levantadas a partir dos financiamentos que foram divulgados pelo MDA após as alterações no Pronaf-Agroindústria, mostrando uma nova face dessa linha de crédito.

Foi financiada uma fábrica de leite em pó no Rio Grande do Sul que conta com 3,6 mil agricultores familiares e mil famílias de assentados, além de nove cooperativas parceiras e quatro associações de produtores, com área de abrangência em 38 municípios gaúchos. O investimento para construção da fábrica totalizou $\mathrm{R} \$ 25,4$ milhões, sendo que $R \$ 10$ milhões foram provenientes do Programa Nacional de Fortalecimento da Agricultura Familiar (Pronaf), linha de crédito Agroindústria. Com a nova torre de secagem de leite em pó, a Cooperativa dará início ao processo de triplicação da sua produção, que passará dos atuais 150 mil para 450 mil litros de leite por dia, totalizando $600 \mathrm{mil}$ litros de leite em pó (MDA/SAF, 18/09/2008). [grifo do autor]

Um projeto de financiamento no oeste de Santa Catarina, feito com apoio do Ministério do Desenvolvimento Agrário (MDA), por meio do Programa Nacional de Fortalecimento da Agricultura Familiar (Pronaf), no valor 
de $R \$ 96$ milhões, via BNDES, vai viabilizar a construção de uma fábrica de processamento de leite em pó. A nova unidade vai ser construída no município de Pinhalzinho (SC) e terá capacidade para processar, diariamente, 650 mil litros de leite em pó e 750 mil litros de soro de leite [...]. A linha de crédito utilizada foi o Pronaf Agroindústria. $O$ projeto foi encaminhado por cinco cooperativas singulares, associadas à Cooperativa Central Oeste Catarinense Aurora, que reúne 17 associações singulares, com 77 mil pequenos e médios produtores, em 332 municípios do estado de Santa Catarina (MDA/SAF, 16/01/2009). [grifo do autor]

Por meio do Programa Nacional de Fortalecimento da Agricultura Familiar (Pronaf), modalidade Agroindústria, foram liberados $R \$ 10$ milhões para a Cooperoeste, de São Miguel do Oeste, formada por 600 associados de 15 assentamentos dessa região. Além de ampliar a capacidade de beneficiamento do leite, que passará de 10 milhões de litros/mês, para 17 milhões de litros/mês, a marca Terra Viva - Produtos da Reforma Agrária - também passará a ser impressa em embalagens de creme de leite e de achocolatados (MDA/SAF, 19/01/ 2009). [grifo do autor]

A situação exposta acima aponta para um novo perfil dos projetos financiados pelo Pronaf-Agroindústria, após as mudanças nas condições de financiamento, em especial a flexibilização dos juros para os agricultores com maiores rendas, o apoio a grandes cooperativas com menor número de produtores familiares e o aumento do teto dos recursos coletivos, como já pôde ser visto. Além disso, deve-se destacar a regionalização dos financiamentos, já que foram $\mathrm{R} \$ 116$ milhões direcionados somente aos estados do Rio Grande do Sul e Santa Catarina.

Tendo por base as notícias oficiais disponibilizadas pelo MDA, resgatadas acima, pode-se averiguar uma reorientação dos rumos tomados por essa linha de crédito, uma vez que perdeu o enfoque exclusivo nos agricultores familiares e nas pequenas agroindústrias. A partir dai, pode-se dizer que houve uma transformação nos princípios básicos do Pronaf-Agroindústria, posto que outrora essa modalidade voltava-se especificamente "às propriedades onde a mão de obra fosse familiar, a matéria-prima e o processamento ocorressem dentro da 
590 - Política Pública de Agroindustrialização na Agricultura Familiar: Uma Análise do Pronafagroindústria

unidade, os resíduos fossem acomodados dentro do estabelecimento e a comercialização dos produtos respeitasse a diferenciação e as especificidades culturais" (Gestor do Programa, Entrev. 2).

Essa flexibilização aponta justamente para as mudanças sobre as características do público a ser beneficiado pela linha de crédito, uma vez que as transformações caminham de encontro ao histórico do Pronaf-Agroindústria. Isso porque a concepção inicial desse mecanismo era "criar formas para contrapor o sistema de integração, incentivando as unidades para que busquem a diferenciação dos produtos agroindustrializados a partir da valorização das especificidades dos territórios e das famílias, inserindo-se em mercados não convencionais" (Gestor do Programa, Entrev. 1). Entretanto, analisando os casos acima em que se tem a presença de mais de 80 mil produtores dentro de três grandes agroindústrias, fica visível o atual desvirtuamento do público e das atividades que se buscava apoiar, pois os agricultores passam a fornecer a matériaprima, mas não atuam no processo de agroindustrialização como se previa inicialmente. Concomitantemente, houve uma mudança nos produtos das agroindústrias, visto que se tratam de mercadorias padronizadas e sem significativa diferenciação, concorrendo, assim, com as multinacionais do setor (Nestlé, por exemplo).

O apoio às grandes cooperativas de leite no cenário recente não impedirá que sejam financiados pequenos empreendimentos familiares por meio do Pronaf. Entretanto, se abriu um grande espaço para novos perfis de beneficiários que já acomodaram, só nesses três projetos, $48,4 \%$ dos recursos que haviam sido investidos por todo o Pronaf-Agroindústria entre 2003/06. Isso significa que os financiamentos das três agroindústrias através do Mais Alimentos alcançou o mesmo valor que havia sido direcionado para 3.623 empreendimentos familiares. Considerando-se essa situação, cabe a questão: qual opção de financiamento é mais viável do ponto de vista da agricultura familiar e do desenvolvimento rural? No caso das grandes agroindústrias de leite, o que se tem são agricultores entregando a matéria-prima para um empreendimento onde participam como cooperados, o que não rompe com a sua situação de integrados e submissos aos interesses empresariais da cooperativa.

Por outro lado, quando se financiam pequenas agroindústrias localizadas no meio rural se agrega uma série de elementos que não são alcançados no caso das grandes cooperativas agroindustriais. Olhando pelo lado do desenvolvimento rural, as unidades de processamento dentro das propriedades possibilitam aos agricultores uma elevada autonomia produtiva, o que reduz a própria vulnerabilidade econômica e social das famílias (ELLIS, 1998). Além 
disso, a presença de uma série de agroindústrias situadas de forma descentralizada no espaço rural gera uma importante dinâmica ocupacional e de fomento às economias locais (MALUF, 2004; MIOR, 2005). Paralelamente, trata-se de empreendimentos familiares que resgatam uma série de valores simbólicos, culturais e históricos no momento da produção e comercialização (WILKINSON, 1999; SILVEIRA e ZIMERMANN, 2004; RAUPP, 2005), além de auxiliar na preservação dos recursos naturais por meio do reaproveitamento dos resíduos da agroindústria dentro da propriedade (PREZOTTO, 2005; NIEDERLE e WESZ JUNIOR, 2008).

\section{Considerações finais}

O surgimento, no final da década de 90 , de uma linha de crédito voltada ao apoio das agroindústrias familiares veio ao encontro de uma demanda latente que existia no Brasil, em especial no Sul do País. Por um lado, os resultados desse mecanismo foram satisfazendo os anseios de uma série de produtores que necessitavam dos recursos para a construção ou ampliação da agroindústria. Por outro, criaram uma nova demanda em agricultores que passaram a reconhecer a importância dessa atividade a partir das facilidades nas condições do financiamento. Nos últimos anos, foi crescente o número de agroindústrias e famílias beneficiadas pelo crédito, fomentando assim uma série de atividades diferenciadas no espaço rural brasileiro. Esse arcabouço se configurou sem depender de elevadas quantidades de recursos por empreendimento, pois os valores dos financiamentos ficaram, em média, quatro vezes abaixo do que havia sido previsto inicialmente.

Desde o momento em que a linha de crédito era chamada de PronafAgregar, passando em 2003 para a denominação de Pronaf-Agroindústria, até a inclusão dessa modalidade no Programa Mais Alimentos, muitas mudanças aconteceram. Uma das alterações está relacionada à taxa de juros, que ao longo dos anos apresentou redução significativa. Embora a queda nessa variável tenha acontecido em todos os grupos de produtores, o seu arrefecimento se deu de forma mais expressiva nos contratos demandados pelos agricultores familiares com menores rendas (os grupos $\mathrm{B}, \mathrm{A} / \mathrm{C} \mathrm{e} \mathrm{C}$ tiveram decréscimo na taxa de juros de $4 \%$ para $1 \%$ ).

Além da alteração da taxa de juros, obteve-se um alastramento no públicoalvo do Pronaf-Agroindústria. A entrada dessa linha de crédito no Programa Mais Alimentos proporcionou uma mudança significativa nos contratos coletivos vinculados à cadeia dos lácteos, onde os beneficiários deixaram de ser 
592 - Política Pública de Agroindustrialização na Agricultura Familiar: Uma Análise do Pronafagroindústria

exclusivamente os agricultores familiares e seus grupos e passaram a fazer parte as grandes cooperativas do setor. A mudança no perfil do público do Pronaf-Agroindústria condicionou uma alteração no valor dos recursos que são acessados coletivamente, uma vez que as condições anteriores não foram mais suficientes para atender às novas características dos demandantes pelo crédito. No caso do processamento de leite e derivados, o montante de recursos disponibilizado por empreendimento cooperativo aumentou 33,7 vezes, pois subiu de $R \$ 720$ mil para $R \$ 25$ milhões.

No caso das grandes cooperativas, dificilmente os agricultores familiares participam das etapas de beneficiamento, pois a sua função principal é a entrega da matéria-prima a partir dos sistemas de integração. Além disso, os produtos são padronizados, livres de qualquer diferenciação e sem nenhuma relação com os espaços locais de produção e processamento, levando essas unidades a disputarem fatias de mercado com as grandes empresas do setor. Diante do elevado nível de concorrência e concentração no segmento de lácteos, a competitividade das cooperativas pode passar pela aquisição de financiamentos com taxas de juros reduzidas e bem inferiores às encontradas no mercado ( $3 \%$ a.a. no caso do Pronaf-Agroindústria). Assim, o Estado garante parte da eficiência da empresa no momento em que arca com o custo financeiro dos baixos juros cobrados, auxiliando um empreendimento que não é, necessariamente, provido das características diferenciadas da agricultura familiar, visto que apenas 55\% da produção de leite precisam ser oriundas dessa categoria social. Desta forma, a flexibilização das condições financeiras do Pronaf-Agroindústria, que foram oficializadas no Plano Safra 2008/09, tornou possível o financiamento de grandes cooperativas sob condições financeiras de agricultores familiares, mesmo quando estes só estão disfarçados desse público.

Em suma, as alterações nas condições de financiamento e o alastramento do público beneficiado parecem ter provocado a dissolução dos princípios iniciais do Pronaf-Agroindústria. Essa situação ficou clara a partir das mudanças supracitadas, pois as cooperativas podem financiar o montante de $R \$ 25$ milhões, enquanto as agroindústrias familiares detêm um valor por contrato próximo aos R\$ 32 mil. Esse rearranjo aponta para a opção atribuída ao PronafAgroindústria de beneficiar, no período recente, os grandes empreendimentos, visto que os recursos que são oferecidos para uma única cooperativa podem financiar cerca de 780 agroindústrias familiares. Portanto, o enfoque da modalidade de crédito deixa de ser exclusivamente as estratégias mais autônomas, onde a gestão e o trabalho são efetivados pela família, e passa a ser também as grandes cooperativas, que, em alguns casos, podem até ser nocivas para a própria sustentabilidade dos agricultores familiares. 


\section{Referências bibliográficas}

AZEVEDO, P. R.; COLOGNESE, S. A. ; SHIKIDA, P. F. A. Agroindústrias familiares no Oeste do Paraná: um panorama preliminar. Organizações Rurais e Agroindustriais - Revista de Administração da UFLA. Lavras - MG, v. 2, n. 1, p. 3-10, 2000.

BRASIL. Programa de agroindustrialização da produção dos agricultores familiares. 2004. Disponível em: <http://www.mda.gov.br/saf> Acesso em: set. de 2007.

BRASIL. Programa de agroindustrialização da produção dos agricultores familiares. 2007. Disponível em: <http://www.mda.gov.br/saf> Acesso em: set. de 2007.

COPETTI, L. D. Fatores que dificultam o acesso dos agricultores familiares às políticas de crédito rural: o caso do Pronaf-Crédito no município de Alegria-RS. Dissertação (Mestrado em Desenvolvimento Rural) Programa de Pós-Graduação em Desenvolvimento Rural, Universidade Federal do Rio Grande do Sul, Porto Alegre, 2007.

ELLIS, F. Household strategies and rural livelihood diversification. The Journal of Development Studies, v. 35, n. 1, p 1-38, 1998.

GUANZIROLI, C.E. Pronaf dez anos depois: resultados e perspectivas para o desenvolvimento rural. In: CONGRESSO DA SOCIEDADE BRASILEIRA DE ECONOMIA E SOCIOLOGIA RURAL, 44. 2006, Fortaleza, CE. Anais... Fortaleza, CE: SOBER, 2006.

GUIMARÃES, G.M.; SILVEIRA, P.R.C.Por trás da falsa homogeneidade do termo agroindústria familiar rural: indefinição conceitual e incoerência das políticas públicas. In: CONGRESSO DA SOCIEDADE BRASILEIRA DE SISTEMAS DE PRODUÇÃO, 7. 2007, Fortaleza, CE. Anais... Fortaleza, CE: 2007.

LEITE, S. Padrão de financiamento, setor público e agricultura no Brasil. In: LEITE, S. (Org.). Políticas Públicas e Agricultura no Brasil. Porto Alegre, Ed. da UNIVERSIDADE, 2001. 
594 - Política Pública de Agroindustrialização na Agricultura Familiar: Uma Análise do Pronafagroindústria

MALUF, R. S. Mercados agroalimentares e agricultura familiar no Brasil: agregação de valor, cadeias integradas e circuitos regionais. Revista Ensaios FEE. 25 (1), 299-322, 2004.

MIOR, L.C. Agricultura familiar, agroindústria e redes no desenvolvimento rural. Chapecó: Argos, 2005.

MIOR, L. C.; WILKINSON, J. Setor Informal, produção familiar e pequena Agroindústria: Interfaces. Estudos Sociedade e Agricultura. Rio de Janeiro, $\mathrm{n}^{\circ} 13,1999$.

MINISTÉRIODO DESENVOLVIMENTO AGRÁRIO(MDA); SECRETARIADA AGRICULTURA FAMILIAR (SAF). Agricultores familiares de Santa Catarina investem em fábrica de leite em pó. Brasília: MAPA, 2009. Disponível em: <http://www.agricultura.gov.br/>. Acesso em: jan. de 2009.

MINISTÉRIO DO DESENVOLVIMENTO AGRÁRIO(MDA); SECRETARIADA AGRICULTURA FAMILIAR (SAF). Pronaf: Cooperativa de assentados amplia indústria de leite. Brasília: MAPA, 2009. Disponível em: <http:// www.agricultura.gov.br/>. Acesso em:jan. de 2009.

MINISTÉRIO DO DESENVOLVIMENTO AGRÁRIO(MDA); SECRETARIADA AGRICULTURA FAMILIAR (SAF). Pronaf financia fábrica de leite em pó no Rio Grande do Sul. Brasília: MDA/SAF, 2008. Disponível em: <http:/ /www.mda.gov.br/>. Acesso em: out. de 2008.

NIEDERLE, P.A.; WESZ JUNIOR, V.J. Possibilidades e limites da agroindustrialização à diversificação dos meios de vida na agricultura familiar: evidências a partir da região Missões-RS. In: COLÓQUIO AGRICULTURA FAMILIAR E DESENVOLVIMENTO RURAL, 2, 2008, Porto Alegre. Anais... Porto Alegre : Edurgs, 2008.

OLIVEIRA, A.A. "PROVE, o gosto da inclusão social”: análise da ação do poder público no processo de implementação do Programa de Verticalização da Pequena Produção Agrícola do Distrito Federal (PROVE). Dissertação (Mestrado em Desenvolvimento, Agricultura e Sociedade) - Programa de Pós-Graduação em Desenvolvimento, Agricultura e Sociedade, Rio de Janeiro, 2000.

OLIVEIRA, J. A. V. de, PREZOTTO, L. L.; VOIGT, L. Diagnóstico e potencial das agroindústrias familiares do Estado do Rio Grande do Sul. Florianópolis/SC, 2002. (Trabalho não publicado). 
OLIVEIRA, J. A. V. de, SCHMIDT, J. A. V.; SCHMIDT, W. Avaliação do potencial da indústria rural de pequeno porte (IRPP) em Santa Catarina. $2^{a}$ ed. Florianópolis: CEPAGRO, 2000.

PREZOTTO, L.L. A agroindústria rural de pequeno porte e o seu ambiente institucional relativo à legislação sanitária. Dissertação (Mestrado em Agroecossistemas) - Programa de Pós-Graduação em Agroecossistemas, Universidade Federal de Santa Catarina, Florianópolis, 1999.

PREZOTTO, L.L. Uma concepção de agroindústria rural de pequeno porte. Revista de Ciências Humanas. Florianópolis, n. 31, p.133-154, 2002.

PREZOTTO, L. L. A sustentabilidade da agricultura familiar Implicações e perspectivas da legislação sanitária para a pequena agroindústria. Fortaleza: Fundação Konrad Adenauer, 2005.

RAUPP, A.K. Políticas públicas e agroindústria de pequeno porte da agricultura familiar: considerações de experiências do Rio Grande do Sul. Dissertação (Mestrado em Desenvolvimento, Agricultura e Sociedade) Programa de Pós-Graduação em Desenvolvimento, Agricultura e Sociedade, Universidade Federal Rural do Rio de Janeiro, Rio de Janeiro, 2005.

SCHMIDT, V. D. B. Agroindústria em Santa Catarina: da integração à inclusão social. In: CONGRESSO DA SOCIEDADE BRASILEIRA DE ECONOMIA E SOCIOLOGIA RURAL, 38, 2000, Rio de Janeiro. Anais... Rio de Janeiro: SOBER, 2000.

SCHNEIDER, S.; CAZELLA, A. A.; MATTEI, L. Histórico, Caracterização e dinâmica recente do Pronaf- Programa Nacional de Fortalecimento da Agricultura Familiar. In: SCHNEIDER, S.; KUNRATH SILVA, M; MORUZZIMARQUES, P. E. Políticas públicas e participação social no Brasil rural. Porto Alegre: Ed. UFRGS, 2004, p. 21-51.

SILVEIRA, P.R.C.; ZIMERMANN, S.A. A qualidade em circuitos regionais de produção de alimentos numa perspectiva de segurança alimentar. In: Froehlich,J.M.; Diesel,V. (Org.). Espaço Rural e Desenvolvimento regional. Ijui-RS: UNIJUI, 2004, p. 217-226. 
596 - Política Pública de Agroindustrialização na Agricultura Familiar: Uma Análise do Pronafagroindústria

VIEIRA, L. F. Agricultura e agroindústria familiar. Revista de Política Agrícola, Brasília, v. VII, n. 1, p.11-23, 1998.

WESZ JUNIOR, V.J. As políticas públicas de agroindustrialização na agricultura familiar: análise e avaliação da experiência brasileira. Dissertação (Programa de Pós-Graduação em Desenvolvimento, Agricultura e Sociedade). Universidade Federal Rural do Rio de Janeiro, Rio de Janeiro, 2009 .

WILKINSON, J. Cadeias produtivas para a agricultura familiar. Organizações Rurais e Agroindústrias. Revista de Administração da UFLA, v. 01, $\mathrm{n}^{\circ} 01$, p. 34-41, 1999. 